\author{
Ghada A Elbaz ${ }^{1 \star}$, Mohamed Sherif $M$ \\ Salah Eldin ${ }^{2}$ and Walaa H M Mabrok ${ }^{3}$ \\ ${ }^{1}$ Assistant Professor of Pediatric and Preventive \\ Dentistry and Dental Puplic Health, Faculty of \\ Dentistry, Suez Canal University, Egypt \\ ${ }^{2}$ Professor of Pediatric and Preventive Dentistry and \\ Dental Puplic Health, Faculty of Dentistry, Suez \\ Canal University, Egypt \\ ${ }^{3}$ Pedodontic in Specialized Dental Center in Port \\ Said, Egypt
}

Dates: Received: 29 October, 2015; Accepted: 10 November, 2015; Published: 12 November, 2015

*Corresponding author: Ghada Abdel Hameed Elbaz, Assistant Professor, 272, South AcademyNew Cairo- Cairo. Egypt. Tel: 00225377084; 00201221092501; Fax: 0643224471; E-mail: Dr.G.baz@live.co.uk

www.peertechz.com

ISSN: 2455-4634

Keywords: Glass ionomer; ART; Autistic spectrum disorder

\author{
Research Article
}

\section{A Comparative Study of the Efficiency of two Different Glass Ionomer Using ART Technique in a Group of Egyptian Children with Autistic Spectrum Disorder}

\begin{abstract}
Aim: The aim of the study was to evaluate and compare the effect of conventional glass ionomer cement and Nano-glass ionomer using atraumatic restorative technique (ART) in a group of Egyptian autistic children.

Materials and Methods: Thirty autistic patients had cavitated lower first primary molars (class I only) were included in this study. According to the type of restorative material used, the children were classified into 2 groups: (Group I) their teeth were restored with conventional glass ionomer, (Group II) their teeth were restored with Nano-glass ionomer (ketac N 100). All children were checked clinically, radio graphically and for bacterial count evaluation at baseline (before treatment) and after 1 week, 2 weeks, 1 month, 3 months and 6 months.

Results: After 6 months, group I showed statistically significant higher prevalence of pain, food stagnation, restoration defects and widening of lamina dura than group II while for bacterial count evaluation, the microbiological assay results show there was no statistically significant difference between the two groups.

Conclusion: The results indicate that Nano-glass ionomer can be considered a successfu alternative restorative material for ART technique with promising results in treatment of children with autistic spectrum disorder.
\end{abstract}

\section{Introduction}

Atraumatic restorative treatment (ART) is an alternative treatment for dental caries used to remove demineralized and insensitive outer carious dentin with hand instruments only. Therefore, no electricity or anesthesia is required and pain, usually experienced in conventional cavity preparation, is kept to a minimum. Originally, ART was developed for use in developing rural countries. More recently, ART has become increasingly accepted in developed countries because of its "atraumatic" approach in relation to the stress and pain experienced by patients [1,2]. ART consists of caries removal using hand instrument combined with the use of a modern restorative material with adhesive characteristics. High viscosity glass ionomer cement (HVGIC) is the material of choice for atraumatic restorative treatment due to properties such as biocompatibility, chemical adhesion to tooth structures, and fluoride release and uptake. HVGICs still have many disadvantages such as final polishing, short working time, slow development of ultimate properties and moisture dehydration resulted in micro-cracks [3-6]. Nano-ionomer is the latest development in a long history of glass ionomer technology. Nanotechnology provides some value added features not typically associated with glass ionomer restorative materials such as improved polish and aesthetics, abrasion resistance, strength, optical properties, and increased fluoride release [7]. Schools or clinics in the community may benefit from ART programs since it requires little setup time and the equipment is portable. It might help to reduce barriers to treatment of patients with disabilities and young and uncooperative children in which fear and anxiety are the reasons behind the unmanageable behaviors of children in the dental chair $[8,9]$.

The prevalence of autism has been increasing drastically over the past few decades. Due to tremendous lack of awareness, this special group is often neglected. Few studies over the past years showed a higher rate of oral diseases among the autistic patients [10]. Autism specifically affects brain function in the areas responsible for the development of communication and social interaction skills. The hallmark of autism is the lack of communication skills. Affected children also have problems with language, behavior and social skills [11]. Most recent studies of centers for Disease Control and Prevention suggest that children who meet the Autistic Disorder criteria range in numbers of up to 12 per 1,000 children, worldwide. Prevalence rates per country are difficult to determine. Wong [12], and Posserud et al. [13], calculated and identified respective country's approximate prevalence rates of autism diagnoses of children living in other countries throughout the world and combined as follows: Australia: 6.25 in 1000, China: 1.1 in 1000, Denmark: Nearly 9 in 1000, India: 1 in 250, Canada: 1 in 154 and Sweden: 1 in 188. In autistic patients unpleasant stimuli, such as the injection of local anesthesia 
or the noise and vibration of rotary instruments, may provoke disproportionate anxiety and subsequent opposition to treatment. In addition, poor muscle coordination, fatigability or oral dysfunction such as drooling and tongue movement, may compromise restorative procedures [14]. Finally ART is almost painless and may be useful to treat children, particularly those who present with management problems, and it could also be extended as an alternative treatment in school dental services, homes for mentally and physically disabled, and the elderly.

The aim of the study was to evaluate and compare the effects of conventional glass ionomer restorative material and Nano-glass ionomer using atraumatic restorative technique (ART) in a group of Egyptian children with autistic spectrum disorder.

\section{Materials and Methods}

Thirty autistic patients aged from 4-6 years [before the eruption of the first molar] who were attending rehabilitation institute (Hack Awladna) under supervision of both Ministry of Social Solidarity and World Health Organization were included in this investigation. Informed written consent for participating in the study was taken from their parents. The protocol of the research project followed the guidelines of scientific committee of Suez Canal University, Faculty of Dentistry (an institutional review board) and has been approved by this committee. The children included in this study fulfilled the following criteria: a-Except for autism, they were apparently healthy children (past and present medical history were taken). B-There was no history of antibiotic intake (4-6 weeks). c-They used to brush their teeth twice daily. d-They were under fiber and protein enriched food, low sugar intake diet. e-They had carious and cavitated lower first primary molars (D) class I only. f-They had no signs or symptoms for pulpal involvement. All children had both clinical and radiographic examination "periapical radiograph" for the carious molars before treatment, also collection of salivary samples by Dentocult strips for streptococcus mutans (SM) were done. The dental caries was measured using the decayed, missed, and filled teeth index (dmft) for primary dentitions, according to the codes and criteria established by the World Health Organization [15]. A tooth was considered decayed when there was frank carious cavitation, as missing if it was extracted due to caries and as filled if it had a restoration for a carious lesion. Exfoliated teeth in the primary and mixed dentition, unerupted, and those extracted for other reasons apart from caries were not included in the indices.

According to the type of restorative material used, the children were classified randomly into 2 groups: (Group I) consisted of 15 children with autistic spectrum disorder; their teeth were restored with conventional glass ionomer (GC AMERICA INC, conventional glass ionomer restorative material). (Group II) consisted of 15 children with autistic spectrum disorder; their teeth were restored with Nanoglass ionomer (3M ESPE-Germany Ketac N 100 restorative kit Nano filling restorative glass ionomer). Each child, accompanied by his/her teacher or even one of the parents, was brought to the examination room and was seated on a comfortable chair in upright position. A tell-show-do technique was used with all the children. Multiple diagnostic kits were used for examination, including plane dental mirror, explorer and tweezers. The examination of the soft and hard tissues was done under flash light and regular room light. The undermined enamel of lower (D) was removed by small chisel, while the soft dentine on both walls and the floor of the cavity was removed by a small spoon excavator. The cavity was rinsed with water using a cotton pellet, making sure that all soft dentine was removed from the cavity. Mixing was done for both types of the glass ionomer materials according to manufacturing instructions. The cavity was filled with the conventional glass ionomer by a condenser while nano-glass ionomer was applied by a special disposable plastic applicator for the kit. The restoration was pressed into the cavity against the walls, and then allowed to be hardened as in the conventional glass ionomer group as it is chemically cured or using light cure for the ketac N 100 group to allow the final setting of the restoration. All children were checked clinically, radio graphically and for bacterial count evaluation at baseline (before treatment) and after 1 week, 2 weeks, 1 month, 3 month and 6 month. Clinical evaluation was done by assessment for pain experience (presence or absence), food stagnation (presence or absence visually) and restoration defects (chipping margins, attrition of restoration, cracked restoration and lost restoration). Radiographic evaluation was done by assessment of any changes of the lamina dura and periradicular area. Bacterial evaluation was done to determine the Streptococcus mutans count in saliva by using Dentocult strips (NORTH BAY/Bioscience, LLC, Orion Diagnostic, Dentocult SM kit) according to the manufacturers' chart. After incubation time, the presence of the Streptococcus mutans was confirmed by detecting light-blue to dark-blue raised colonies on the inoculated surface of the strip. Colonies suspended in the culture broth were excluded from the evaluation. The microbiological results were evaluated according to the manufacturers' chart (Figure 1). Qualitative data were presented as frequencies and percentages. Chi-square (x 2) test was used for comparisons between the two groups. The significance level was set at $\mathrm{P} \leq 0.05$. Statistical analysis was performed with $\mathrm{IBM}^{\circledR}$ SPSS $^{\circledR}$ Statistics Version 20 for Windows.

\section{Results \\ Clinical evaluation}

Pain experience: Table 1 illustrates that, at baseline as well as

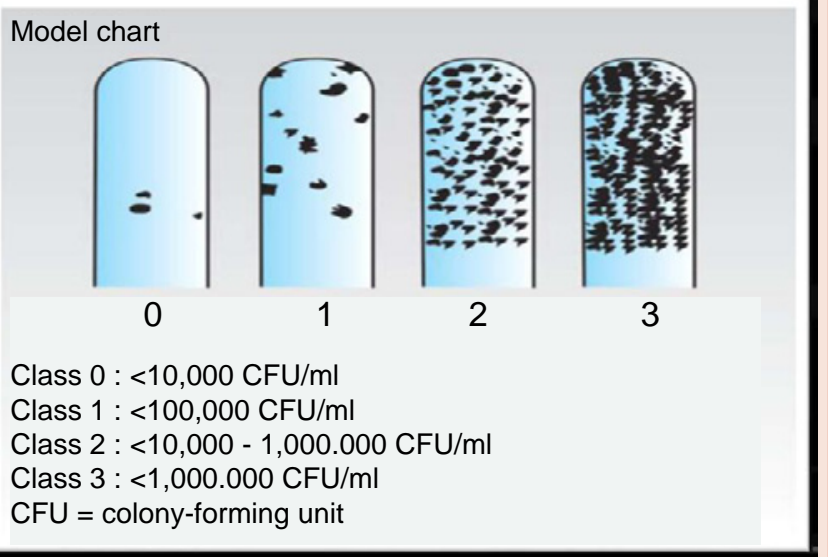

Figure 1: Manufacturers' chart. 
Table 1: Comparison between the frequencies and percentages (\%) of pain at different time period in the 2 groups by Chi-square test.

\begin{tabular}{|c|c|c|c|c|c|}
\hline \multirow{2}{*}{$\begin{array}{l}\text { Group } \\
\text { Time }\end{array}$} & \multicolumn{2}{|c|}{$\begin{array}{l}\text { Group I Conventional GI } \\
\qquad(n=15)\end{array}$} & \multicolumn{2}{|c|}{$\begin{array}{c}\text { Group II Ketac N100 } \\
(\mathrm{n}=15)\end{array}$} & \multirow[t]{2}{*}{ P-value } \\
\hline & $\mathbf{N}$ & $\%$ & $\mathbf{N}$ & $\%$ & \\
\hline Baseline & 2 & 13.3 & 3 & 20 & 0.624 \\
\hline After 1 week & 2 & 13.3 & 1 & 6.7 & 0.543 \\
\hline After 2 weeks & 0 & 0 & 0 & 0 & $\mathrm{NC}+$ \\
\hline After 1 month & 0 & 0 & 0 & 0 & $\mathrm{NC}+$ \\
\hline After 3 months & 5 & 33.3 & 0 & 0 & $0.014^{*}$ \\
\hline After 6 months & 6 & 40 & 1 & 6.7 & $0.031^{*}$ \\
\hline
\end{tabular}

after 1 week, there was no statistically significant difference between prevalence of pain in the 2 groups. After 2 weeks as well as 1 month, there was no pain in the two groups while after 3 months as well as after 6 months, group I showed statistically significant higher prevalence of pain than group II.

Food stagnation: Table 2 illustrates that, at baseline, all cases showed food stagnation in both groups. After 1 week, 2 weeks as well as 1 month, there was no food stagnation in the 2 groups while after 3 months as well as after 6 months, group I showed statistically significantly higher prevalence of food stagnation than group II.

Restoration defects: Table 3 illustrates that, after 1 week, 2 weeks as well as 1 month, all cavities in the 2 groups showed no defects. After 3 months, group I showed statistically significantly higher prevalence of defects than group II, the 6 defects found in conventional GI group comprised 5 restoration showed slight attritions and 1 cracked restoration. After 6 months, conventional GI showed statistically significantly higher prevalence of defects than Ketac N100, the only defect found in Ketac N100 group was fractured margin while the 7 defects found in conventional GI group comprised 6 cracked restorations and 1 lost restoration.

\section{Radiographic evaluation}

Widening of lamina dura: Table 4 illustrates that, widening of lamina dura was observed only after 6 months. Conventional GI showed statistically significantly higher prevalence of widening of lamina dura than Ketac N100.

Periradicular pathosis: Table 4 illustrates that, only one case of (group I) have periradicular pathosis after 6 month period.

\section{Bacterial evaluation (streptococcus mutans) counts}

Figure 2 illustrates that, at baseline $(<100,000)$ while after 1 week, 2 weeks, 1 month as well as 3 months, both groups showed the same Dentocult results $(<10,000)$. After 6 months, there was no statistically significant difference between the 2 groups.

\section{Discussion}

In this study, 30 children with autistic spectrum disorder were under supervision of both Ministry of Social Solidarity and World Health Organization (WHO) were included in this investigation because it makes the follow up easier and more regular and their trainers were helping in the examination. All included children had to be accompanied by his or her teacher or parents as the autistic children feel more comfortable and cooperative in presence of their teachers or parents. They were examined clinically, radio graphically and for bacterial count by using Dentocult (SM) kit before the treatment (baseline), 1 week, 2 weeks, 1 month, 3 months and 6 months after the treatment. Dentocult (SM) is one of the best ways for the detection of streptococcus mutans counts, as (SM) is responsible for the initiation of dental caries because of its ability to adhere to the tooth surface. So using Dentocult (SM) is better than Dentocult lactobacillus (LB). Moreover, this test is chair side, more patient compliance especially for disabled young age, minimal armamentarium needed, less time consuming and easy sample collection [16,17]. Davenport et al. [18], compared Dentocult (SM) kit with conventional method and found

Table 2: Comparison between the frequencies and percentages (\%) of food stagnation at different time period in the 2 groups by Chi-square test.

\begin{tabular}{|c|c|c|c|c|c|}
\hline \multirow{2}{*}{ Group } & \multicolumn{2}{|c|}{$\begin{array}{c}\text { Group I Conventional GI } \\
(\mathbf{n = 1 5 )}\end{array}$} & $\begin{array}{c}\text { Group II Ketac N100 } \\
\text { (n= 15) }\end{array}$ & \multirow{2}{*}{ P- value } \\
\cline { 2 - 6 } Time & $\mathbf{N}$ & $\mathbf{\%}$ & $\mathbf{N}$ & $\%$ & \\
\hline Baseline & 15 & 100 & 15 & 100 & NC† \\
\hline After 1 week & 0 & 0 & 0 & 0 & NC† \\
\hline After 2 weeks & 0 & 0 & 0 & 0 & NC† \\
\hline After 1 month & 0 & 0 & 0 & 0 & NC† \\
\hline After 3 months & 6 & 40 & 0 & 0 & $0.006^{*}$ \\
\hline After 6 months & 6 & 40 & 1 & 6.7 & $0.031^{*}$ \\
\hline
\end{tabular}

*: Significant at $\mathrm{P} \leq 0.05,+\mathrm{NC}$ : Not computed because the variable is constant

Table 3: Comparison between the frequencies and percentages (\%) of restoration defects at different time period in 2 groups by Chi-square test.

\begin{tabular}{|c|c|c|c|c|c|}
\hline Group & $\begin{array}{c}\text { Group I Conventional GI } \\
\text { (n= 15) }\end{array}$ & $\begin{array}{c}\text { Group II Ketac N100 } \\
\text { (n= 15) }\end{array}$ & \multirow{2}{*}{ P- value } \\
\cline { 2 - 6 } & $\mathbf{N}$ & $\mathbf{\%}$ & $\mathbf{N}$ & $\%$ & \\
\hline After 1 week & 0 & 0 & 0 & 0 & NC† \\
\hline After 2 weeks & 0 & 0 & 0 & 0 & NC† \\
\hline After 1 month & 0 & 0 & 0 & 0 & NC† \\
\hline After 3 months & 6 & 40 & 0 & 0 & $0.006^{*}$ \\
\hline After 6 months & 7 & 46.6 & 1 & 6.7 & $0.031^{*}$ \\
\hline
\end{tabular}

*: Significant at $\mathrm{P} \leq 0.05,+\mathrm{NC}$ : Not computed because the variable is constant

Table 4: Comparison between the frequencies and percentages (\%) of widening of lamina dura and Periradicular pathosis in 2 groups at 6 months by Chi-square test.

\begin{tabular}{|c|c|c|c|c|c|}
\hline & \multicolumn{3}{|c|}{$\begin{array}{c}\text { Group I Conventional } \\
\text { GI (n= 15) }\end{array}$} & $\begin{array}{c}\text { Group II Ketac } \\
\text { N100 (n= 15) }\end{array}$ & P- value \\
\hline & N & $\%$ & N & $\%$ & \\
\hline lamina dura & 6 & 40 & 1 & 6.7 & $0.031^{*}$ \\
\hline Periradicular pathosis & 1 & 6.7 & 0 & 0 & $0.309^{*}$ \\
\hline *: Significant at P $\leq 0.05$ & \multicolumn{7}{|l}{} \\
\hline
\end{tabular}

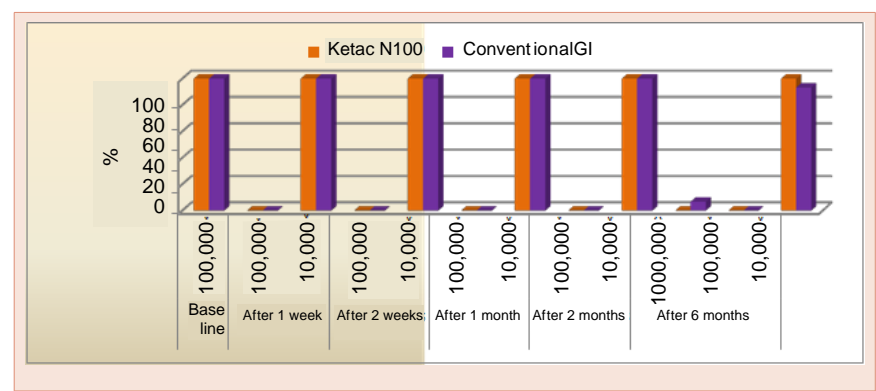

Figure 2: Bar chart representing Dentocult results in the two groups. 
these dip-slide tests provide a simple and suitable method of screening salivary Streptococcus mutans level, which may have a useful role in caries risk assessment. In a similar study, the sensitivity, specificity and accuracy of Dentocult SM were better than the conventional methods [19]. The split-mouth design is a popular design in oral health research. In the most common split-mouth study, each of two treatments are randomly assigned to either the right or left halves of the dentition [20]. The attractiveness of the design is that it removes a lot of inter-individual variability from the estimates of the treatment effect but in our study this design cannot be used because the antibacterial effect of each restorative material should be evaluated separately.

Concerning the pain experience results, it was found that, at the baseline as well as after 1 week, 2 weeks and 1 month there was no statistically significant difference between prevalence of pain in the 2 groups, this may be due to the sealing of the prepared cavities with filling materials and elimination of the cariogenic bacteria. After 3 months as well as after 6 months, group I showed statistically significant higher prevalence of pain than group II. The results of the present study agreed with previous investigations of Lee et al. [21], who reported that, post-operative sensitivity resulted from the presence of carious dentin and the low quality of the adhesive bond to dentin, the deficient bond caused marginal gaps and consequently, micro leakage, recurrent caries and pulp inflammation.

Regarding to the results of food stagnation, all cases of the 2 groups at baseline time showed food stagnation, and this may be due to presence of cavitated molars. After 1 week, 2 weeks as well as 1 month, there was no food stagnation in the 2 groups but after 3 months as well as after 6 months, conventional GI showed statistically significant higher prevalence of food stagnation than Ketac N100, it may be due to high surface hardness of Nano-glass ionomer than conventional glass ionomer, resulting in decreased surface attrition that may cause food stagnation.

Concerning the restoration defects, after 3and 6 months, Conventional GI showed statistically significant higher prevalence of defects than ketac N100. This may be resulted from high muscular tonicity of autistic patients that may have caused high occlusal forces and low hardness of the conventional glass restoration. This finding is in consistence with the results of Konde et al. [22], who indicated that Nano-glass ionomer restoration were significantly better than glass ionomer restoration in case of cavo-surface marginal discoloration and marginal adaptation. Several previous studies demonstrated that, autistic patients whose age was 4 years old experienced excessive grinding and clenching of teeth as well as muscular in-coordination of the tongue. There is also the challenging media we are dealing with; excessive salivation, tongue movement, gingival bleeding and difficulty accepting rubber dam that may all result in contamination of a prepared cavity by saliva that may interfere with the adhesiveness of the glass ionomer. Both saliva and blood will reduce the adhesive properties of the restorative material used $[9,23]$.

In this study in (group II), widening of lamina dura wasn't observed except after 6 months in one case, while in (group I) there was widening of lamina dura in 6 patients, and only one case showed periapical pathosis. This may be due to increase in restoration defects that occurred in conventional glass ionomer group (group I) compared to katac N 100 (group II) after six months.

Concerning the bacterial count by Dentocult strips for both groups, there was significant decrease in Streptococcus Mutans count from baseline in relation to different time periods. This result is in accordance with previous studies $[24,25]$ who reported that, there was a significant reduction of SM levels in saliva immediately after 1 week following the ART approach using Fuji IX glass ionomer. Concerning the bacterial count of conventional glass ionomer group (group I) there was a significant difference between the baseline and the end of six month period. While for ketac N100 group (group II), there was no statistically significant difference between Dentocult results at different time periods. This may be due to the high incidence of restoration defects in group I that lead to increased failure rate of the conventional glass ionomer group than in ketac N100 group. This finding goes with the results of Roshan et al. [24], who reported that, there was significant difference between baseline and 6 months period. Although the mean SM counts remained less than the baseline after 6 month evaluation, a trend toward re-establishment of SM to the baseline count was noticed. This study had some limitations as it was started with 60 children with autistic spectrum disorder, only 30 patients completed the study. This was due to lack of cooperation of their parents, missing the follow up appointments and difficulty in communication with the child.

\section{Conclusion}

The results indicated that nano-glass ionomer (ketac N 100) can be considered a successful alternative restorative material for ART technique with promising results in the treatment of children with autistic spectrum disorder.

\section{Acknowledgement}

We thank all children participating in this study, their parents and the staff of Hack Awladna for their patience, understanding and real help. The study did not receive any funding.

\section{References}

1. Frencken J, Songpaisan $Y$, Phantumvanit P, Pilot T (1994) An atraumatid restorative treatment (ART) technique: Evaluation after one year. Internationa Dental Journal 44: 460-464.

2. Carvalho TS, Ribeiro TR, Bönecker M, Pinheiro EC, Colares V (2009) The atraumatic restorative treatment approach: An "atraumatic" alternative. Med Oral Patol Oral Cir Bucal 14: 668-673.

3. Frencken J, Pilot T, Songpaisan Y, Phantumvanit P (1996) Atraumatio estorative treatment (ART): Rationale, technique, and development. J Publid Health Dent 56: 135-143.

4. Mallow PK, Durward CS, Klaipo M (1998) Restoration of permanent teeth in young rural children in cambodia using the atraumatic restorative treatment (ART) technique and fuji II GI cement. Int J Paediatr Dent 8: 35-4j.

5. Yip HK, Smales RJ, Yu C, Gao XJ, Deng DM (2002) Comparison of atraumatic estorative treatment and conventional cavity preparations for glass-ionomen restorations in primary molars: One-year results. Quintessence Int 33: 17-21.

6. De Souza EM, Cefaly DF, Terada RS, Rodrigues CC, de Lima Navarro MF (2003) Clinical evaluation of the ART technique using high density and resinmodified glass lonomer cements. Oral Health Prev Dent 1: 201-207. 
7. Markovic DL, Petrovik BB, Peric TO (2008) Fluoride content and echargeability of five glass ionomer dental materials. BMC Oral Health 8 : $1-21$.

8. Cumella S, Ransford N, Lyons J, Burnham H (2000) Needs for oral care among people with intellectual disability not in contact with the Community dental services.Journal of Intellectual Disability Research 44: 45-52.

9. Molina GF, Faulks D, Frencken JE (2013) Suitability of ART approach for managing caries lesions in people with disability. Acta Odontol Scand 71:1430-1435.

10. Vajawat M, Deepika PC (2014) Comparative evaluation of oral hygiene practices and oral health status in autistic and normal individuals. J Int Sod Prev Community Dent 197: 132-211.

11. Barbaresi WJ, Katusic SK, Voigt RG (2006) Autism: A review of the state of the science for pediatric primary health care clinicians. Arch Pediatr Adolesc Med 160: 1167-1175.

12. Wong VC, Hui SL (2008) Epidemiological study of autism spectrum disorder n China. J Child Neurol 23: 67-72

13. Posserud M, Lundervold AJ, Lie SA, Gillberg C (2010) The prevalence of autism spectrum disorders: Impact of diagnostic instrument and nonesponse bias. Soc Psychiatry Psychiatr Epidemiol 45: 319-327

14. Lee HH, Milgrom P, Starks H, Burke W (2013) Trends in death associated with pediatric dental sedation and general anesthesia. Paediatr Anaesth 23 . 741-746.

15. World Health Organization (1987) Oral health surveys: basic methods, 3rd edit. Geneva: WHO.

16. Shi S, Liang Q, Hayashi Y, Yakushiji M, Machida Y (1998) The relationship between caries activity and the status of dental caries-application of the Dentocult SM method. Chin J Dent Res 1: 52-55.
17. Shi S, Deng Q, Hayashi Y, Yakushiji M, Machida Y, et al. (2003) A follow-up study on three carries activity tests. J Clin Pediatr Dent 27: 359-364.

18. Davenport ES, Day S, Hardie JM, Smith JM (1992) A comparison between commercial kits and conventional methods for enumeration of salivary mutans streptococci and lactobacilli. Community Dent Health 9: 261-271

19. Karjalainen S, Soderling E, Pienihakkinen K (2004) Validation and nterexaminer agreement of mutans streptococci levels in plaque and saliva of 10-year-old children using simple chair-side test. Acta Odontologica Scandinavica 62: 153-157.

20. Lesaffre E, Philstrom B, Needleman I, Worthington $\mathrm{H}$ (2009) The design and analysis of split-mouth studies: what statisticians and clinicians should know. Statistics in Medicine 28: 3470-3482

21. Lee IB, Son $\mathrm{HH}$, Um CM (2003) Rheologic properties of flowable,conventional hybrid, and condensable composite resins. Dent Mater 19: 298-307.

22. Konde S, Raj S, Jaiswal D (2012) Clinical evaluation of a new art material: Nanoparticulated resin-modified glass ionomer Cement. J Int Soc Prev Community Dent 2: 42-47.

23. Muthu MS, Prathibha KM (2008) Mangment of a child with autism and sever bruxism: a case report. J Indian Soc Pedod Prev Dent 26: 82-84.

24. Roshan NM, Shigli AL, Deshpande SD (2010) Microbiological evaluation o salivary streptococcus mutans from children of age 5-7 years, pre-and postatraumatic restorative treatment. Contemp Clin Dent 1: 94-97.

25. Tegginmani VS, Goel B, Uppin V, Horatti P, Kumar LS, et al. (2013) Comparison of Antibacterial Activity of Glass-Ionomer Cement and Amalgam n Class Two Restoration by Streptococcus Mutans Count Analysis in Fixed Intervals: in vivo study. J Contemp Dent Pract 14: 381-386. 